\title{
Phrasal and clausal comparatives in Greek and the abstractness of syntax*
}

\author{
Jason Merchant \\ University of Chicago \\ merchant@uchicago.edu
}

\begin{abstract}
Greek phrasal and reduced clausal comparatives differ in that the former, but not the latter, show island sensitivities. In neither case, however, is the material that constitutes the island pronounced. This paper argues that such facts can only be captured by positing abstract unpronounced syntactic structures; the comparison between the two kinds of comparatives further shows that reducing the island effects to semantic or other ill-formedness is not possible: the island effects are irreducibly syntactic. Such facts provide support for syntactic architectures that countenance this kind of abstractness, and against surfacist syntactic theories.
\end{abstract}

\section{Keywords}

clausal comparatives, island effects, phrasal comparatives, syntax

\section{Introduction}

One of the recurrent leitmotifs of theorizing in many domains, including syntax, is that simple surface appearances can be misleading, and that underlying apparently simple elements or phenomena, we find complex and intricate relations and structures. This paper explores one such domain, that of comparatives, and shows that in at least one language, namely Greek, these constructions, which appear on the surface quite simple, actually make use

* My greatest thanks go to Anastasia Giannakidou, without whose intuitions and advice this paper could not have been written, as well as to the numerous native speakers I interviewed in Greece in the summers of 2006 and 2007 who supplied intuitions on the data reported on herein. Thanks also to Rajesh Bhatt, Brian Joseph, Chris Kennedy, Howard Lasnik, Shoichi Takahashi, Susanne Winkler, and the reviewers for comments and questions and helpful suggestions for improvement as well as to audiences at Stanford, Michigan, Maryland, Tübingen, and Potsdam, and in Seoul, Albuquerque, and Ioannina, where versions of this material were presented. This research was supported in part by a grant to the author by the Alexander S. Onassis Foundation, which is gratefully acknowledged. 
of a complex syntax, subject to a process which masks their complexity and gives rise to their surface simplicity. It is argued that such an analysis is necessary to account for the facts of this construction, and that no theory or analysis which attempts to keep the syntax too simple can have a successful account of the facts. The argument itself is simple: effects which are generally believed to be due to complex syntactic dependencies, namely island sensitivities, are attested in Greek phrasal comparatives, and these island sensitivities cannot plausibly be attributed to semantic difficulties. These facts indicate that even in apparently simple phrasal comparatives, there must be syntactic movement. Two equally effective possibilities are shown to capture this: first, the phrasal comparatives may have a clausal source, subject to movement constraints and to ellipsis; or, second, the correlate of the pivot of comparison may move at an abstract level of syntactic structure. The analysis crucially relies on the availability of abstract, unpronounced syntactic structures and provides a direct argument for grammatical architectures that countenance such abstractness. Surfacist approaches cannot make the required distinctions.

\section{Clausal and phrasal comparatives}

Clausal comparatives are comparatives in which the complement of the marker of the standard of comparison (e.g., than in English) shows clausal syntax, consisting of all the usual elements found in a clause whose only gap is that which corresponds to the comparative operator. In English, these have the following form.

(1) Mary plays the guitar better than John plays the guitar.

(2) More people live in Russia than live in the US.

(3) In the 2000 presidential election in Florida, more people thought they voted for Gore than thought they voted for Bush.

In Greek, clausal comparatives have the same properties; note that the standard marker corresponding to English than is ap'oti.

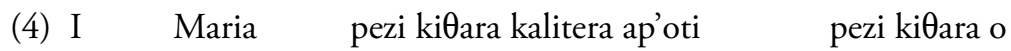
the Maria.NOM plays guitar better than.CLAusal plays guitar the Giannis.

Giannis.NOM

'Maria plays the guitar better than Giannis plays the guitar.'

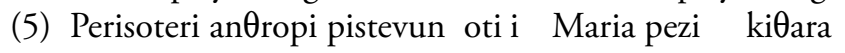
more people think.3pl that the Maria plays guitar 
ap'oti pistevun oti pezi violi.

than.Clausal think.3pl that play.3sg violin

'More people think that Maria plays guitar than think that she plays violin.'

Phrasal comparatives, on the other hand, contain only a single phrase following the standard marker, as in (6).

(6) a. Mary plays the guitar better than John.

b. Mary reads more books than John.

c. More people like Mary than John.

In English, this than has been argued by Hankamer (1973) to be a preposition, based on its ability to be stranded under wh-movement, as in (7), and the ability of reflexives bound by the subject of the adjective to appear after it, as in (8).

(7) Who is Mary taller than?

(8) No-one is taller than himself.

In Greek, such phrasal comparatives appear as in (9).

(9) a. I Maria pezi kiӨara kalitera apo ton

the Maria.NOM plays guitar better than.PHRASAL the

Gianni.

Giannis.ACC

'Maria plays the guitar better than Giannis.'

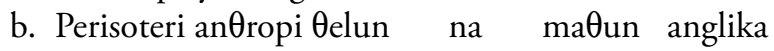

more people want.3p suBJ learn.3p English

apo germanika.

than.PHRASAL German.

'More people want to learn English than German.' (lit. 'More people want that they learn English than German.' $)^{1}$

Greek is thus an ideally revealing language, since it distinguishes phrasal from clausal comparatives in the marker of the standard of comparison (in addition to other ways we'll see directly). The phrasal comparative marker is

\footnotetext{
${ }^{1}$ Note that $n a$, which is glossed here as subj for subjunctive, is often assumed to be a complementizer, as it is in complementary distribution with the indicative nonfactive complementizer $o t i$ and the factive complementizer $p u$. Whether $n a$ is or is not a complementizer is not relevant to this argument: crucial is only that the embedded clause is finite, showing full subject-verb agreement and permitting nominative subjects; Greek lacks infinitivals. See PhilippakiWarburton 1993, Roussou 2000, and Giannakidou 2009 for recent contributions to the extensive literature on these elements.
} 
the preposition apo, while the clausal one is the complex ap'oti, which consists of a reduced form of $a p o$, $a p$ ', with an invariant $o t i$, which in other contexts is the external head of certain free relatives.

(10) standard markers ${ }^{2}$

\begin{tabular}{ll}
\hline phrasal & clausal \\
\hline apo & ap-oti \\
from & from-wh(free relative) \\
than.PHRASAL & than.CLAUSAL \\
\hline
\end{tabular}

While Greek does not allow for preposition stranding under wh-movement, other tests for prepositionhood indicate that the Greek phrasal comparatives are as prepositional as their English counterparts, if anything more clearly so. First, the standard marker is apo, which in other uses is a preposition meaning 'from, of, by' (such as in (11)).

(11) a. I Maria erxete apo tin A $\theta$ ina. the Maria.NOM is.coming from the Athens.ACC

'Maria is coming from Athens.'

b. To ðoro apo ton Gianni irӨe. the gift from the Giannis.ACC arrived 'The gift from Giannis arrived.'

c. To paraӨiro anikse apo mono tu. the window opened by lonesome its

'The window opened by itself.'

In all uses, what follows apo must be a single DP in the accusative case, as we expect from a preposition. This is true even in cases like (9a), where the standard of comparison corresponds to a notional subject. Data from the distribution of reflexives and pied-piping under wh-movement similarly show that apo in phrasal comparatives is a preposition. First, pied-piping is possible in phrasal comparatives, as shown in (12). Second, to the extent that locality conditions on the licensing of reflexives indicates a monoclausal domain, the possibility of the Greek bound reflexive anaphor $o$ eaftos $t u$ after apo, seen in (13), provides further evidence for the prepositional nature of apo in these structures. ${ }^{3}$ And third, emphatic negative polarity items like kanenas are licensed by matrix negation after apo (Giannakidou 1998).

${ }^{2}$ For reasons of analytical focus, ap-os-o /i/... and para clausal markers will not be discussed here, though they share many properties with ap'oti clauses; see Xeila-Markopoulou 1986, Giannakidou and Yoon 2008, and Giannakidou and Stavrou 2009.

3 Though see Anagnostopoulou and Everaert 1999 for a more refined look, which does not, however, affect the point made here. 
(12) Apo pjon (ipes oti) epekse kalitera kifara i than.PHRASAL whom (said.2sg that) played better guitar the Maria $\quad \mathrm{x} \theta \mathrm{es}$ ?

Maria.Nom yesterday

'Than whom did (you say that) Maria play(ed) guitar better yesterday?'

(13) Kanenas ${ }_{1}$ ðen ine psiloteros apo [ton eafto tu] $]_{1}$. $n$-person not is taller than.PHRASAL the self his

'No-one is taller than himself.'

(14) O Giannis ðen ine psiloteros apo kanenan. the Giannis not is taller than.PHRASAL n-person 'Giannis isn't taller than anyone.'

What we can call reduced clausal comparatives can look at first sight quite similar to phrasal comparatives in a language like English; they contain generally a single phrase following the standard marker:

(15) More people live in Russia than in the US.

(16) More people thought they voted for Gore than for Bush.

What distinguishes reduced clausal comparatives from true phrasal ones is the fact that a non-DP may follow than. In addition, multiple phrases may occur after than as well:

(17) a. Amy likes to play the guitar loudly more than quietly.

b. More people like to watch movies than climb mountains.

(18) Amy plays the guitar better than Sam the violin.

There is therefore an analytical ambiguity in examples like (6): these may be true phrasal (prepositional) comparatives, or reduced clausal ones; for such examples it is generally impossible to determine which, in English.

In Greek, however, reduced clausal comparatives are much simpler to identify. While they also may have one or more phrases following the standard marker, this marker is ap'oti, not apo, and what follows the standard marker can be any category consistent with its understood role in the clause. This includes the possibility that the standard is a DP in the nominative, as in (19a).

(19) a. I Maria pezi kiӨara kalitera ap'oti o the Maria. NOM plays guitar better than.ClAUSAL the Giannis.

Giannis. NOM

'Maria plays the guitar better than Giannis plays the guitar.'

b. Perisoteri anӨropi nomizan oti psifisan ton Gore more people thought that they.voted.for the Gore.ACC 
ap'oti ton Bush.

than.CLAUSAL the Bush.ACC

'More people thought that they voted for Gore than thought they voted for Bush.'

In a reduced clausal comparative, the case of a DP following ap'oti must in fact be the case that its correspondent in a non-reduced clausal comparative would have: for a contrasting subject, for example, the case must be nominative (compare (20a) with the phrasal (9) above). When such a nominative appears, the phrasal marker apo is impossible, as seen in (20b).

(20) a. * I Maria pezi kiӨara kalitera ap'oti ton the Maria.NOM plays guitar better than.CLAUSAL the Gianni.

Giannis.ACC

'Maria plays the guitar better than Giannis plays the guitar.'

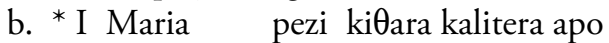

o

the Maria. NOM plays guitar better than.PHRASAL the

Giannis.

Giannis.NOM

'Maria plays the guitar better than Giannis plays the guitar.'

As in English, non-DP and multiple remnants are possible only with reduced clausal comparatives:

(21) a. Perisoteri antropi menun stis IPA ap'oti sti more people live in.the USA than. CLAUSAL in.the

Rosia.

Russia

'More people live in the US than in Russia.'

b. Perisoteri anӨropi milisan me ton Gianni tin Kyriaki

More people spoke with the Giannis the Sunday

ap'oti me ton Anesti to Savato.

than.Clausal with the Anestis the Saturday

'More people spoke with Giannis on Sunday than with Anestis on Saturday.'

(22) a. * Perisoteri anOropi menun stis IPA apo sti more people live in.the USA than.PHRASAL in.the

Rosia.

Russia

('More people live in the US than in Russia.') 
b. * Perisoteri anӨropi milisan me ton Gianni tin Kyriaki more people spoke with the Giannis the Sunday apo me ton Anesti to Savato. than.PHRASAL with the Anestis the Saturday

('More people spoke with Giannis on Sunday than with Anestis on Saturday.')

Finally, the tests that diagnose a close connection between the marker and what follows it yield the opposite results with apoti comparatives from their apo congeners above:

(23) * Ap'oti pjos (ipes oti) epekse kalitera kiOara i than.ClaUsAl who (said.2sg that) played better guitar the Maria $\quad \mathrm{x} \theta \mathrm{es}$ ?

Maria.nom yesterday

(lit. 'Than who did (you say that) Maria play(ed) guitar better yesterday?')

(24) * Kanenas, ${ }_{1}$ Jen ine psiloteros ap'oti [o eaftos tu $]_{1}$. n-person not is taller than.Clausal the self his (lit. 'No-one is taller than himself.')

(25) * O Giannis ðen ine psiloteros ap'oti kanenas. the Giannis not is taller than.CLAUSAL n-person (lit. 'Giannis isn't taller than anyone.')

In sum, Greek clearly distinguishes on morphological and other grounds between phrasal comparatives with apo and clausal comparatives (both full and reduced) with ap'oti. Their contrasting properties are summarized in the following table, where I use "pivot" to denote the phrase which immediately follows the marker of comparison (in other words, the standard of comparison):

(26) Properties of apo vs. ap'oti comparatives

\begin{tabular}{llc}
\hline & apo & ap'oti \\
\hline allows only one pivot? & yes & no \\
allows only DP pivot? & yes & no \\
always marks pivot with accusative? & yes & no \\
allows pied-piping? & yes & no \\
allows reflexive binding from matrix clause? & yes & no \\
licenses negative concord from matrix clause? & yes & no \\
\hline
\end{tabular}




\section{Standard analyses}

The standard analyses of these various comparatives, as exemplified by, among many others, Hankamer (1973) and Kennedy (1999; 2002) (also see Lechner 2001, 2004 for extensive discussion), posit that phrasal comparatives have the syntax of simple PPs, as in (27), while reduced clausal comparatives involve movement of a remnant to a clause-external (or clause-peripheral) position concomitant with clausal ellipsis, as in (28). Elided material here and below is enclosed in angled brackets $(<>)$; in these structures, representation of the comparative operator itself and of its clause-internal trace is suppressed. ${ }^{4}$

(27) a. Abby plays guitar better $\left[{ }_{\mathrm{PP}}\right.$ than $\left[_{\mathrm{DP}}\right.$ Ben] $]$.

b. I Maria pezi ki $\theta$ ara kalitera $\left[_{\mathrm{PP}}\right.$ apo $\left[_{\mathrm{DP}}\right.$ ton the Maria plays guitar better than.PHRASAL the Gianni]].

Giannis.ACC

'Maria plays the guitar better than Giannis.'

(28) a. More people live in Russia than [ $[\mathrm{pP} \text { in the US }]_{2}<$ live $\left.t_{2}>\right]$.

b. I Maria pezi kiӨara kalitera ap'oti [ [ o the Maria plays guitar better than.CLAUsaL the Giannis $]_{3}<\left[_{\text {TP }}\right.$ pezi kithara $\left.\left.t_{3}\right]>\right]$. Giannis.NOM plays guitar 'Maria plays guitar better than Giannis does.'

The movement analysis for reduced clausal comparatives is supported by the fact that preposition pied-piping is obligatory for remnants whose correlates are objects of prepositions. Greek requires that DP objects of prepositions pied-pipe the preposition in all movement structures, including the leftward movement found in 'focus'-movement, topicalizations, question formation, and relative clauses. (See parallel data from sluicing in Greek discussed in Merchant 2000; 2001.)

(29) a. I Maria milai me ton Petro pjo sixna ap'oti the Maria speaks with the Petro.ACC more often than.CLAUSAL

$\left[\left[_{\mathrm{PP}} \text { me ton Gianni }\right]_{1}<\left[_{\mathrm{TP}}\right.\right.$ milai $\left.\left.t_{1}\right]>\right]$. with the Giannis.ACC speaks

'Maria talks with Petros more often than with Giannis.'

${ }^{4}$ In fact, as noted above, ap'oti can fairly plausibly be analyzed as $a p(o)+o t i$, where $o t i$ is a comparative operator, parallel to the invariant wh-head for neuter free relatives, oti, and is presumably in specCP, where I place it in the fuller tree structures below. But for reasons of simplicity, and since the movement of the comparative operator itself is not the focus of this paper, I omit indicating its origin site with a trace. 
b. * I Maria milai me ton Petro pjo sixna the Maria speaks with the Petro.ACC more often ap'oti $\quad\left[\left[_{\mathrm{DP}} \text { ton Gianni }\right]_{2}<\left[_{\mathrm{TP}}\right.\right.$ milai me $\left.\left.t_{2}\right]>\right]$. than.CLAUSAL the Giannis.ACC speaks with ('Maria talks with Petros more often than Giannis.')

The ungrammaticality of (29b) is expected if the DP remnant ton Gianni has illicitly moved from within its PP, violating the ban on P-stranding in Greek.

\section{Unexpected island sensitivities}

The conceptually appealing and straightforward standard analyses lead us to the following expectation: since phrasal comparatives are just PPs without movement, and since reduced clausal comparatives involve movement of the remnant, we should find island effects in reduced clausal comparatives but not in phrasal ones. In Greek, in fact, we find just the opposite set of facts:

(30) Phrasal comparatives in Greek show island effects.

Reduced clausal comparatives do not.

This can be seen on the basis of the following data. In each doublet, the element following the standard marker contrasts with a phrase, internal to an island in the main clause (a relative clause, a temporal adjunct, and a sentential subject, respectively). When this phrase occurs in a reduced clausal comparative with apoti (the (a) examples), the structure is grammatical; when it is in a phrasal comparative with the preposition apo (the (b) examples), it is not.

(31) Perisoteri antropi menun sto kratos pu kivernai o Putin more people live in.the state that governs the Putin

a. ap'oti o Bush. than.CLAUSAL the Bush.NOM

b. * apo ton Bush. than.PHRASAL the Bush.ACC

'More people live in the country that Putin governs than live in the country that Bush governs."

5 This example was tested in a written questionnaire administered to eight native speakers of Greek in Katerini, Greece, in August 2007; respondents were asked to rate the example sentences on a scale of 1 (=unacceptable) to 5 (=completely normal). The mean score for example (a) was 3.5 , while the mean for (b) was 1.63 . 
(32) O Nikos evlepe perisoteres tenies otan tu tis sistine the Nikos saw more movies when him them recommended i Nana the Nana

a. ap'oti i Elena. than.CLAUSAL the Elena.NOM

b. * apo tin Elena. than.PHRASAL the Elena.ACC

'Nikos saw more movies when Nana recommended them to him than he saw when Elena recommended them to him.'

(33) To oti o pritanis prokite na kalesi tin kaقaristria ine perisotero the that the dean is.going to invite the cleaner is more aksioperiergo noteworthy

a. ap'oti tin Maria. than.Clausal the Maria.ACC

b. * apo tin Maria. than.PHRASAL the Maria.ACC

'That the dean is going to invite the cleaning lady is more noteworthy than that he is going to invite Maria.'

These facts are just the opposite of what the standard analysis predicts. Reduced clausal comparatives, since they involve movement of a remnant, should be sensitive, not insensitive, to islands. Phrasal comparatives, on the other hand, since they involve by hypothesis no movement at all, should not show syntactic island effects. The fact that these latter do show island sensitivities cannot be due to semantic effects: this is shown most simply by the fact that the intended meaning is indeed expressible, both in the reduced clausal version (the (a) examples of (31)-(33)), as well as in fully clausal comparatives involving no ellipsis at all.

(34) Perisoteri anOropi menun sto kratos pu kivernai o Putin more people live in.the state that governs the Putin ap'oti menun sto kratos pu kivernai o Bush. than.Clausal live in.the state that governs the Bush.NOM 'More people live in the country that Putin governs than live in the country that Bush governs.'

(35) O Nikos evlepe perisoteres tenies otan tu tis sistine the Nikos saw more movies when him them recommended 
i Nana ap'oti

the Nana than. CLAUSAL

evlepe otan tu tis sistine i

Elena.

Elena.NOM

'Nikos saw more movies when Nana recommended them to him than he saw when Elena recommended them to him.'

(36) To oti o pritanis prokite na kalesi tin kaAaristria ine perisotero the that the dean is.going to invite the cleaner is more aksioperiergo ap'oti ine to oti prokite na kalesi tin noteworthy than.CLAUSAL is the that is.going to invite the Maria.

Maria.ACC

'That the dean is going to invite the cleaning lady is more noteworthy than that he is going to invite Maria is.'

The same point is made by the English translations of (31)-(33), which involve no reductions and which express the intended, but unavailable, readings of the (b) examples in (31)-(33). ${ }^{6}$

\section{An argument for the abstractness of syntax}

One prima facie conclusion one could draw from these facts would be to claim that 'reduced clausal' comparatives in Greek do not involve movement at any level of representation in the syntax. Such an approach is taken by a number of analysts for a similar range of data involving sluicing and fragment answers. But this leaves the island sensitivity of the phrasal comparatives a mystery, if these do not involve movement either. The puzzle is that there is an uneven distribution of island effects, and that a uniform approach to missing material (as surfacist syntax approaches advocate) seems unable to account easily for the discrepancies. In essence, what I propose is that there is movement of a phrase (in addition to movement of the comparative operator in some cases) in both reduced clausal and in phrasal comparatives. It also seems unlikely that the attested differences in grammaticality are due to the information structure properties of the antecedent, a possibility argued for in detail in Ambridge and Goldberg (2008) for plain extraction from certain islands, since these are invariant across the antecedents: in other words, the antecedent clauses are all the same, which means that the observed differences in

\footnotetext{
${ }^{6}$ Nor are these island effects likely to be due to processing concerns (see Phillips 2006).
} 
acceptability among the types of comparatives must be due to properties of those clauses themselves, and not to their notional antecedents.

In reduced clausal comparatives, the movement is of the remnant, just as traditional analyses posit, which accounts directly for the P-stranding effects (a pattern that analyses that eschew movement have trouble with). The puzzle here is why this movement fails to trigger island effects: for this, I assimilate the movement in reduced clausal comparatives to that found in sluicing, which is equally insensitive to islands. The relevant background and its application to reduced clausal comparatives is given in section 5.1 .

For phrasal comparatives, I explore two analytical possibilities, both of which involve movement of a phrase in a syntactic representation which is only countenanced in non-surfacist approaches to syntax: either the remnant moves overtly in a structure which goes unpronounced (the ellipsis approach, given in section 5.2), or the correlate moves covertly in a structure which does not correspond to the structure pronounced (the LF-movement approach, given in section 5.3). I lay out the details of both approaches, and their respective strengths and weaknesses, but in my view the Greek data alone do not permit a definitive choice between them. What these two approaches do have in common is a necessary reliance on abstract syntactic representations; it is these kinds of representations that surfacist theories of syntax do not allow. Therefore, regardless of which of these approaches to the island sensitivity of phrasal comparatives in Greek one prefers, a surfacist approach to syntax cannot be adopted.

\subsection{Reduced clausal comparatives}

To understand the analysis of the island insensitivity of Greek reduced clausal comparatives, it is necessary to first review the extant approaches to the variable island behavior in other apparently elliptical constructions.

\subsubsection{Elliptical repair in sluicing, VP-ellipsis, and fragment answers}

As famously first noted by Ross (1969), sluicing seems to ameliorate island violations; while (37) exhibits a standard (here, relative clause) island effect, its counterpart in (38) with sluicing shows no comparable deviance.

(37) *Ben wants to hire someone who speaks a Balkan language, but I don't remember which he wants to hire someone who speaks.

(38) Ben wants to hire someone who speaks a Balkan language, but I don't remember which.

Broadly speaking, there are two classes of solution to this problem: ones that maintain that island effects are syntactic and therefore seek to refine the 
syntactic representations or the island mechanisms, and ones that deny that an account of island effects needs access to syntactic representations.

The first class, dating back to Ross (1969) and Chomsky (1972), seeks to assign the amelioration to a result of the ellipsis, generally by a fine-tuned analysis of the syntactic nature of the island effects themselves (or by finetuning the requirements for parallelism in such structures, where the ellipsis allows for a wider range of possible parallelisms than the nonelliptical structure does; Chung et al. 1995, Fox and Lasnik 2003, and Park 2004 represent this sub-strand). A recent approach along these lines is Merchant $(2004 ; 2008)$, which claims that intermediate traces of island-violating wh-movement are illicit (technically, PF-uninterpretable, assuming a Late Insertion model and assuming that the resulting feature bundle is unrealizable by the morphology, following Kennedy and Merchant's (2000) approach to Left Branch effects). All such approaches also seek to capture the fact that wh-extraction out of VP-ellipsis sites is much more restricted, and does not amnesty islands:

(39) *Abby wants to hire someone who speaks a Balkan language, but I don't remember which Ben does. (=<want to hire someone who speaks $>$ )

Merchant's proposal for these cases is that an illicit intermediate trace survives $v \mathrm{P}$ deletion (in VP-ellipsis), but that TP-deletion (in sluicing) eliminates all such traces. Technically, 'ellipsis' is the interpretation of a dedicated feature (E) that can appear on certain functional heads (e.g., $\mathrm{C}$ in sluicing and $\mathrm{T}$ in VP-ellipsis), and whose interpretation at PF is that of syncope (the effect of eliminating its complement from the PF structure: in other words, no node internal to 'ellipsis site' is required to, or allowed to, undergo Vocabulary Insertion). The crucial intermediate trace is labeled ${ }^{*} t_{2}^{\prime \prime}$ in (40).

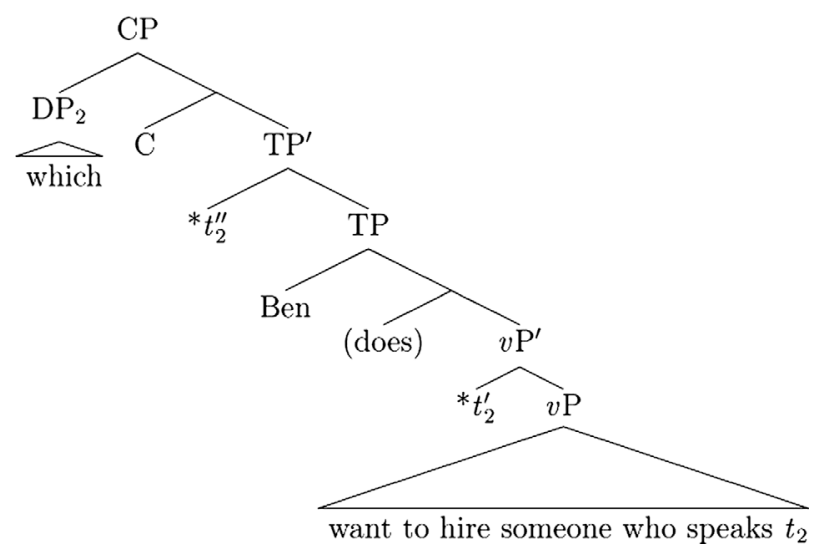


In (40), ellipsis of the complement of C (i.e., sluicing) eliminates all *traces from the PF-interpreted object (in particular, neither ${ }^{*} t_{2}{ }_{2}$ nor ${ }^{*} t_{2}^{\prime}$ reach the PF interface, since they are both contained in the node 'deleted', namely TP'). In VP-ellipsis, on the other hand, deletion of the complement of T, namely $v \mathrm{P}^{\prime}$, leaves ${ }^{*} t_{2}^{\prime \prime}$ in the syntactic object submitted to Vocabulary Insertion at PF; this trace, however, is illicit: the lexicon lacks any item that corresponds to its feature bundle, by hypothesis. It is the persistence of this trace that accounts for the deviance of (39).

For the purposes of this paper, I state the analysis in terms of these illicit intermediate traces, though nothing hinges on this: the analysis should be identical if a different approach to the contrast between (38) and (39) is adopted. Since some of the technical details may be overwhelming, let me reiterate: whatever accounts for the difference in island sensitivity between larger ellipses (such as in sluicing) and smaller ellipses (such as VP-ellipsis) should extend as well to the difference in sensitivity between reduced clausal comparatives and phrasal ones.

While the differing amount of remaining structure in sluicing vs. VP-ellipsis is obvious, similar effects can be found where the remaining structure has no phonological exponence, in particular in the analysis of certain fragment answers such as (41).

(41) a. A: Did each candidate try to feed questions to the journalist who will ask him 1 about abortion (at the debate)?

b. B: ${ }^{*}$ No, about foreign policy.

c. cf. B: No, each candidate ${ }_{1}$ tried to feed questions to the journalist who will ask him 1 about foreign policy.

Merchant (2004) proposes to assimilate the island effects found in such fragment answers to those found in VP-ellipsis as in (39) by taking advantage of additional functional structure on the left periphery. In that proposal, the fragment answer is moved to the specifier of a functional head on the left periphery, above what is taken to be a CP through whose specifier the fragment also moves. The ellipsis in fragment answers targets the clausal node which is complement to the (lower) $\mathrm{C}$, not $\mathrm{F}$. In island-violating movement, the ellipsis of TP leaves a ${ }^{*}$-trace, namely $t_{2}^{\prime}$ in (42), in the object interpreted at $\mathrm{PF}$, leading to the ill-formedness of $(41 \mathrm{~b})$; the resulting tree, with angled brackets indicating the elided TP, is as follows.

Despite the fact that neither $\mathrm{F}$ nor $\mathrm{C}$ contains pronounced material, their presence is necessary to provide the requisite structure for the successive cyclic $\mathrm{A}^{\prime}$-movement of the PP about foreign policy and to host the ill-formed 
$(42)$

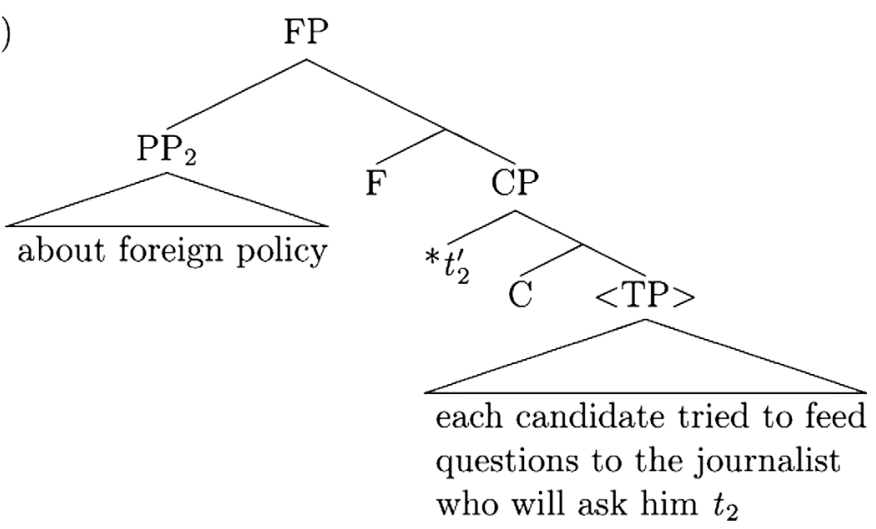

intermediate trace ${ }^{*} t_{2}^{\prime}$. It is such additional structure that will prove instrumental in understanding the Greek phrasal comparative facts.

While attributing island effects and in particular their amelioration in certain circumstances (such as under sluicing) to a refined syntax may be the most common approach to Ross's discoveries, there is a second line of analysis that eschews such abstractness entirely; I call such analyses surfacist. On a surfacist account, the absence of island effects in most cases of sluicing is attributed to the simple fact that there is no wh-movement posited at all, and indeed no syntactic structure at all beyond that of the pronounced material. Since there is no syntax internal to the 'ellipsis', there is a fortiori no violation of syntactic islands. This surfacist strand of analysis is represented in Levin 1982, Ginzburg and Sag 2000, Culicover and Jackendoff 2005, and Jäger 2006. Note that on such approaches, it is the sometime reemergence of island sensitivities, as in (39) (such cases first noted in Sag 1976) or in (41), that is a puzzle. Culicover and Jackendoff (2005) do not discuss cases in which sluicing or VP-ellipsis retains island effects (see Chung et al. 1995, Merchant 2001, Fox and Lasnik 2003, Kennedy 2003, Lasnik and Park 2003, and Park 2005 for such cases), but they do adduce numerous examples of fragment answers with island-internal correlates parallel in general structure to (41) which lack detectable island effects. At this point, our understanding of the relevant phenomena is too rudimentary to give a satisfying account of why some fragment answers require structures like (42) while others, such as those in Culicover and Jackendoff (2005), do not. It seems likely to me that nonelliptical base-generation of certain fragments is possible (see also Schlangen 2003 and Stainton 2006), and that factors of varying strengths preclude such structures when linguistic antecedents are available (as mooted in Merchant 2006). A crucial point to bear in mind in this connection is that the contrasts cannot easily be attributed to 
obvious semantic processing or other semantic or pragmatic effects, as the intended meanings are indeed expressible with slight variations in syntactic means (such as (41c) for (41b)). And while there are several accounts of island effects which propose islands are not syntactic in nature (Kuno and Robinson 1972, Erteschik-Shir 1973; 2007, Kluender 2004, Ambridge and Goldberg 2008), it is not clear to me how they would extend to the differences in the Greek data, which, in neither case is an island structure apparent.

\subsubsection{Overt movement in reduced clausal comparatives}

The above analysis of the differences in island sensitivities in sluicing (generally insensitive) vs. VP-ellipsis and fragment answers (generally sensitive) leads directly to a way of capturing the attested differences along the same dimension in the Greek reduced clausal (insensitive to islands) vs. phrasal (sensitive) comparatives. In this section, I focus only on the insensitive reduced clausal comparatives.

Recall first that the standard analysis of reduced clausal comparatives, adopted with minor modifications here, posits movement of the remnant to a clause-external position with ellipsis of the clausal node, as in (43b) for an example like (43a), repeated from above.

(43) a. Perisoteri antropi nomisan oti psifisan ton Gore

more people thought.3p that voted.for.3p the Gore. ACC

ap'oti ton Bush.

than.CLAUSAL the Bush.ACC

'More people thought that they voted for Gore than (thought that they voted for) Bush.'

b.

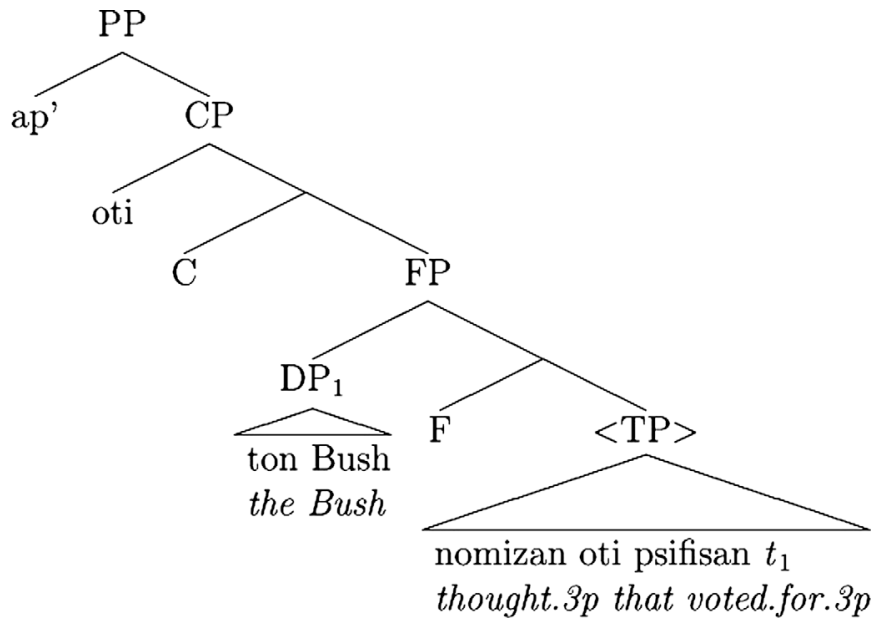


Since reduced clausal comparatives fail to show island effects, the ellipsis must be comparable to that found in sluicing, targeting a node which contains any potential illicit intermediate traces. As in sluicing, the simplest way to achieve this result is to analyze the elided node as the complement to the head whose specifier is the landing site for the remnant. For an example containing an island, then, such as (31a), repeated here, the relevant structure will be that in $(44 \mathrm{~b})$.

(44) a. Perisoteri anӨropi menun sto kratos pu kivernai o Putin more people live in.thestate that governs the Putin ap'oti o Bush. than.Clausal the Bush.NOM

(lit.) 'More people live in the country that Putin governs than (live in the country that) Bush (governs).'

b.

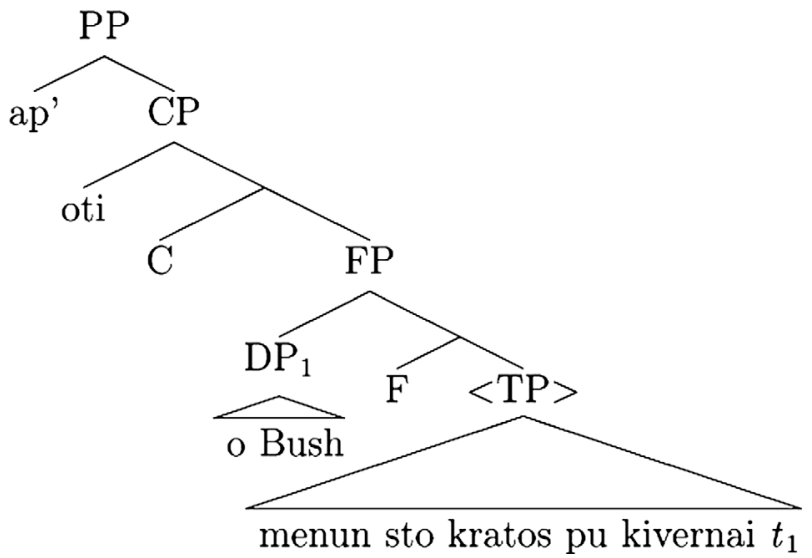

The lack of island effects in reduced clausal comparatives then follows: although the remnant (here, $o$ Bush) has indeed moved out of an island, no illicit intermediate traces remain outside the ellipsis site (they are all internal to the deleted TP, just as in the sluicing case above ${ }^{7}$ ). Again, it is not the mere

\footnotetext{
${ }^{7}$ As a reviewer notes, the movement of the remnant here must co-occur with ellipsis, as such movement is not required in non-reduced clausal comparatives such as the examples in (34)-(36) above. Such mutual dependency between ellipsis and a movement out of the ellipsis site is familiar from fragment answers and swiping, both of which also illustrate cases where an otherwise unneeded or unavailable movement is required when ellipsis occurs. Coding such co-occurrence restrictions is straightforward, if not always deeply illuminating (see Merchant 2004, van Craenenbroeck and Lipták 2006, and Aelbrecht 2009 for details).
} 
fact that an island-violating movement has occurred (it has), it is the resulting structure which is either judged deviant or nondeviant according to the grammatical principles that we posit for ${ }^{*}$-marking traces of island-violating movement.

\subsection{Phrasal comparatives, option 1: Overt movement}

For phrasal comparatives, the apparent puzzle is the reverse: how can there be island effects in the absence of movement? I propose that the island effects are due, in fact, to movement after all. This section presents the first of two implementations of this idea.

Extending the above ellipsis analysis to phrasal comparatives is straightforward, but requires that we posit that, although they appear to have a simple surface structure consisting only of a PP, Greek phrasal comparatives embed an abstract, unpronounced clausal syntax. This analysis thus follows in spirit the earliest transformational analysis of comparatives, Harris (1957: 166), in positing a clausal structure even for apparently surface-simple PP comparatives (despite it being 'intuitively abhorrent' in the words of Ross 1967: 24). Exactly this claim in fact is defended at great length in Lechner $(2001 ; 2004)$, who discusses the numerous advantages such an analysis has for a range of cases in English and German.

On the representational theory of islands laid out above, this would mean that at least one illicit intermediate trace of $A^{\prime}$-movement remains outside the ellipsis site in a phrasal comparative. The easiest way to implement this intuition is if the remnant DP moves out of the CP complement of apo 'than'. Such a movement is most straightforwardly accounted for if the preposition is embedded in a $p \mathrm{P}$ shell (as in Matsubara 2000; for the general claim that the traditional 'PP' contains a number of projections, see also Koopman 2000, Bợšković 2004); the remnant can then move to specPP, while the P itself moves to $p$ (see the discussion on nested PP structures for Greek in Theophanopoulou-Kontou 1992 and Terzi 2005). The resulting structure is that in (45b) for a phrasal comparative such as (45a), repeated from (31b) above.

(45) a. * Perisoteri antropi menun sto kratos pu kivernai o Putin more people live in.the state that governs the Putin apo ton Bush.

than.PHRASAL the Bush.ACC

'More people live in the country that Putin governs than live in the country that Bush governs.' 


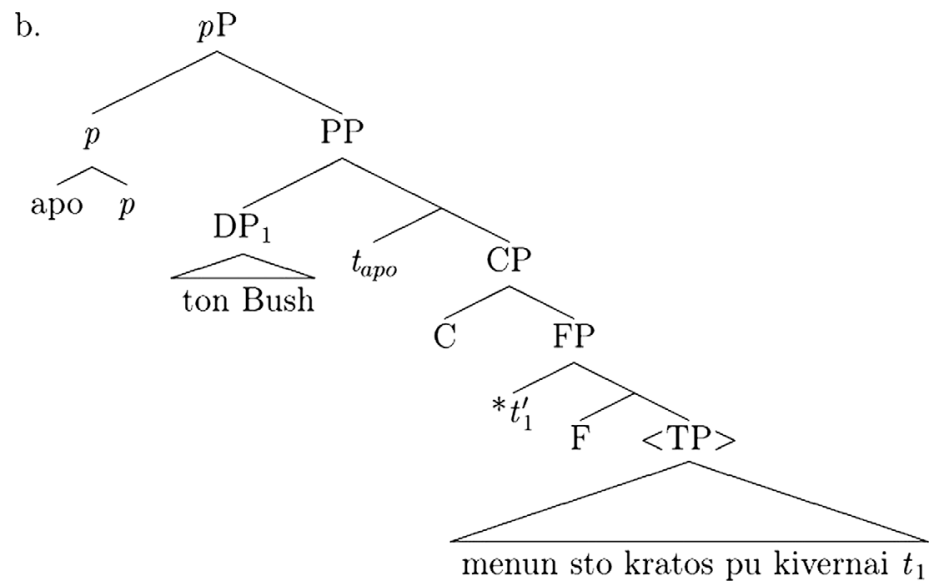

The illicit trace, ${ }^{*} t_{2}^{\prime}$, is outside the elided TP (marked by angled brackets), and hence triggers a PF crash for the same reasons such structures are ruled out in the fragment answer and VP-ellipsis cases discussed above. It is the presence of this intermediate trace that results in the observed island sensitivity.

For simple phrasal comparatives which do not involve extraction out of an island, the licit structure is that in (46b), for examples like (46a). Here, the intermediate traces cause no trouble, as the movement that generated them is not island-violating.

(46) a. I Maria pezi kiOara kalitera apo ton the Maria. NOM plays guitar better than.PHRASAL the Gianni.

Giannis.ACC

'Maria plays guitar better than Giannis.'

b.

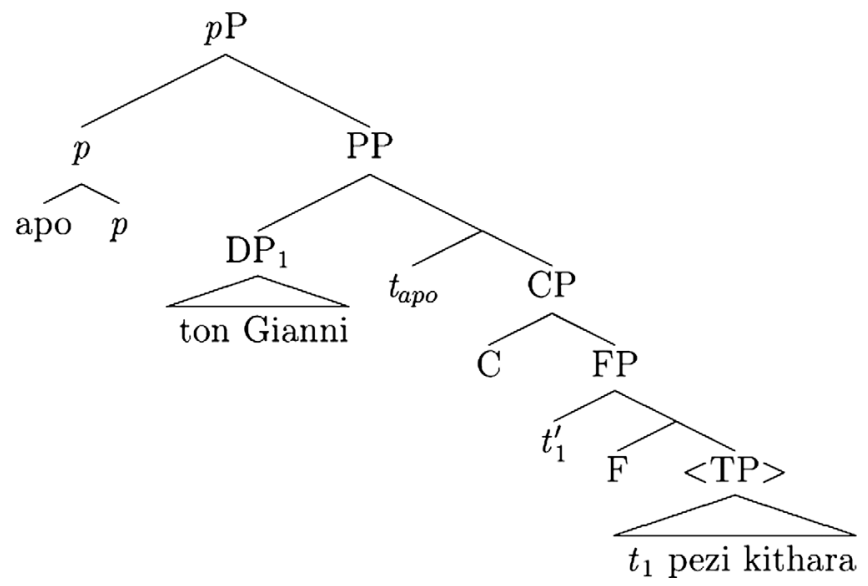


This structure merits more detailed comment. Note first that it is essentially one way of instantiating the basic claim of Lechner $(2001$; 2004) that 'phrasal' comparatives embed a clausal domain. Though the details differ slightly, the present facts dovetail with Lechner's arguments for this conclusion. ${ }^{8}$ They are also compatible with Lechner's counterarguments to Hankamer's proposal for a simple prepositional than (i.e., one that selects simply a DP, not a CP). Recall that the DP following apo behaves like the object of a preposition with respect to wh-pied-piping, reflexive licensing, negative concord licensing, category, and case. The former two facts were illustrated in (12) and (13) above, repeated here:

(47) Apo pjon (ipes oti) epekse kalitera kiOara i

than.PHRASAL whom (said.2sg that) played better guitar the

Maria $\mathrm{x} \theta \mathrm{es}$ ?

Maria.NOM yesterday

'Than whom did (you say that) Maria play(ed) guitar better yesterday?'

Kanenas ${ }_{1}$ den ine psiloteros apo [ton eafto tu] $]_{1}$.
$n$-person not is taller than.PHRAsal the self his

'No-one is taller than himself.'

These facts indicate that the post-apo DP is local in the relevant senses to elements in the matrix clause. These locality effects are accounted for in the present account by the raising of the remnant into the higher domain of $\mathrm{P} / p$ : wh-pied-piping becomes possible (since the wh-feature on the remnant can be passed to the $\mathrm{P} / p$ under whatever implementation of feature percolation or Agree is adopted for prepositional pied-piping), and reflexive binding in this raised position is licit (since no clausal node intervenes between the matrix subject and the anaphor in its higher position).

Next, it is a fact that the remnant in phrasal comparatives is necessarily a single DP (despite the fact that other, and multiple, categories can in principle serve as remnants under stripping-like operations, and in particular are found in reduced clausal comparatives with ap'oti as seen above). This fact is attributable

\footnotetext{
${ }^{8}$ The primary differences between the present structures and Lechner's are two. First, the account given here of island sensitivity requires more structure internal to the standard clause; in particular, it requires an FP and an ellipsis operation beyond that of the across-the-board extraction Lechner uses. Second, the top of the tree is more articulated here: the DP remnant's case is determined by apo. Lechner, discussing only English and German, does not consider languages in which phrasal and clausal comparatives are marked with different standards of comparison and also assumes that default case assignment will correctly handle the in his account otherwise caseless remnant in some situations: while his analysis is well suited to uniform languages like English and German, more must be said to account for Greek.
} 
to several factors. First, if specPP can host only one phrase, as a general property of prepositions in Greek (they take only one complement), the absence of multiple remnants in phrasal comparatives follows. Second, no category other than $\mathrm{DP}$ can raise to specPP, either because the raising itself is triggered by a categoryspecific strong feature (say, a specifier selectional feature $\mathrm{D}$, or a strong inflectional feature $\mathrm{D}^{*}$ ), or because no other category would be able to participate in an Agree relation with the Case feature on $p$ (leading to an 'inverse Case filter' violation on $p$, if Case must be checked or 'deleted' on the Case-assigning headfor example, if Case is uninterpretable on the assigning head).

The local relation between $p$ and the remnant is also expressed in the case on the remnant, which is accusative, assigned under Agree from $p$. It raises an interesting question regarding the assignment and realization of case features; DPs raised in this manner out of finite clauses surface with the Case determined by the higher Case-assigning head, here accusative. This is so despite the fact that the DP may have received a different value for its Case feature internal to the CP; in (46), for example, the DP first receives nominative inside TP, then raises into specPP where it receives accusative, the latter determining the morphological realization. This is precisely the conclusion reached by Bejar and Massam (1999) on the basis of independent evidence, primarily from Niuean. They show convincingly that there exist a range of cases in which DPs receive first one (structural) case before raising into the domain of a second (structural) case assigner, and that it is the latter that determines the morphological form of the DP in Niuean-type languages. Greek patterns with Niuean in this respect, spelling out the Case features on the head of the movement chain, in Bejar and Massam's terms. They propose two parameters relating to the nature of the Case feature and the Spell-Out of Case features in chains; for present purposes, it need only be the case that Case values in Greek can be overwritten. (Alternatively, Greek may allow for more than one Case shell-KP in Bittner and Hale's 1996 system, similar to those found in casestacking languages like Korean or Kayardild as described by Yoon (2004) and Evans (1995) respectively.) The fact that such multiple case assignment can occur in languages like Greek and Niuean but not in English is most likely related to the fact that the former languages have also been claimed to allow raising out of finite clauses (see Alexiadou and Anagnostopoulou 1999 for recent discussion of Greek, and Bejar and Massam 1999 for Niuean; see Legate 2008 and Merchant 2009 for related discussion).

The proposal that a DP may raise into a prepositional domain from a clausal one differs only in detail from those made for Irish in McCloskey 1984, for French in Kayne 2004, and for Greek in Joseph 1979; 1990. Joseph (1990), for example, shows that Greek allows raising out of finite (subjunctive) clauses 
into the case-marking domain of the preposition me 'with', as in the following example, which preserves the idiomatic reading (Joseph 1990: 14):

(49) $\mathrm{Me}$ ton kombo na ftani sto xteni etsi, i lisi with the knot.ACC SUBJ reach.3s to.the comb thus the solution.NOM faneronotan. manifested.3s

'With things coming to a head in this way, the solution was becoming evident.' (lit. 'With the knot thus reaching the comb, ...')

In this example, the DP ton kombo (lit. 'the knot') raises out of the finite subjunctive clause, where it receives nominative case, into the domain of the preposition me where it receives accusative.

Finally, note that movement of the remnant into P's domain is necessarily concomitant with ellipsis of the lower TP: in other words, the phrasal comparative standard marker apo requires the ellipsis of the embedded clause. This co-dependency is parallel in most respects to that found in fragment answers, and is easily captured by positing that that feature that allows movement of the remnant into specFP is part of the same feature bundle as the E feature that triggers ellipsis. It is this FP which is selected by the $\mathrm{C}$ head under apo, and we can suppose that apo itself selects, indirectly, for this feature (through a variant of the $\mathrm{C}$ that occurs in comparatives); this is similar in essence to the kind of selection into an extended projection familiar from Romance, in which verbs can select for subjunctive through what appears to be an inert, or at least invariant, complementizer.

In sum, on this variant of the analysis, Greek phrasal comparatives embed a fully clausal domain; the DP remnant in such structures raises out of the elided clause and becomes a prepositional object. If this movement violates locality constraints such as islands, the resulting phrasal comparative will be ill-formed, specifically, because of the presence of an illicit intermediate trace, on the theory of island repair adopted here. It is crucial in this analysis that the element in specFP, in a phrasal comparative (as in (46b)), be a trace of movement; a prolepsis analysis, in which the accusative-marked DP merely 'controls' or binds a null operator in specFP, is insufficient if the claim in Merchant $(2004 ; 2008)$ is right that only intermediate traces (i.e., non-head elements in a movement chain) host the ${ }^{*}$-feature; in that analysis, heads of chains (such as the wh-phrase in sluicing) themselves do not trigger island

9 Xeila-Markopoulou (1986: 125) claims similarly that apo can assign case to the specifier of its complement, but she doesn't note the 'double-case' problem this leads to. 
effects (see Merchant 2001; 2008 for discussion of the details of implementation of this system). If they did, sluicing, for example, would not alleviate islands, since the pronounced wh-phrase would also be *-marked. Under this system, then, we conclude that it is the DP from the lower clause itself that moves into the higher prepositional domain. ${ }^{10}$

In reduced clausal comparatives, on the other hand, the movement is simply to a clause-external position, similar to that found in sluicing and some fragment answers; any island effects are ameliorated by the ellipsis of the node containing the illicit intermediate traces.

\subsection{Phrasal comparatives, option 2: Covert movement}

The other analytical possibility for accounting for the locality properties of Greek phrasal comparatives is to flip the above account on its head and attribute these effects not to overt movement of the remnant after apo, but rather to covert movement of the correlate in the main clause.

Such an analysis of phrasal comparatives is obviously compatible with the data that shows that the object of the preposition in phrasal comparatives does indeed behave like a prepositional object (see the table in (26) above). But on this account, there are two different comparative morphemes, one for the clausal (both reduced and non-reduced) comparatives (which relates two sets of degrees), and another one for the phrasal comparatives (which relates two individuals to a function from individuals to degree expressions).

It is this three-place comparative morpheme, $-e^{3}{ }^{3}$ or $p j o^{3}$ (given in one possible version in (50); see Bhatt and Takahashi 2008 for a slightly different version), that forces the correlate of the standard of comparison to undergo covert movement to a higher position by an application of Quantifier Raising or the like (as posited in Reinhart 1991). For a simple English example like that in (51a), the result is the LF phrase structure in (51b). In these structures,

${ }^{10}$ On the other hand, a reviewer points out that the posited movement does have another property that bears closer scrutiny, since one might think that specFP in the clausal left periphery is an $\mathrm{A}^{\prime}$-position, while specPP is an A-position, and that therefore the movement from the first to the second would be an instance of improper movement. Of course, the classic ban on improper movement was merely an observation that had no status in the theory, and ruling out improper movement has remained a challenge; the most promising reduction seems to me to be in terms of the number of case features that can be checked: in English, only one per DP, allowing for the possibility that other languages can check more and perhaps don't have the same restriction. Indeed, this seems to be exactly the conclusion we need for a language like Greek, if movement out of finite CPs always proceeds through a specifier of CP (and from there into an A-position in the cases discussed in Alexiadou and Anagnostopoulou 1999). 
the standard of comparison-German here-is also assumed to end up high in the tree, whether base-generated there or moved; see Bhatt and Pancheva 2004 for relevant discussion. The semantic representation of the TP is given in (51c) and the final result after $\lambda$-conversion is the formula in (51d).

$$
\llbracket-e r^{3} \rrbracket=\lambda D_{<e, d t>} \lambda x_{e} \lambda y_{e}\left[\exists d[[D(x)](d)] \wedge\left[d>\max \left(\lambda d^{\prime}\left[[D(y)]\left(d^{\prime}\right)\right]\right)\right]\right]
$$

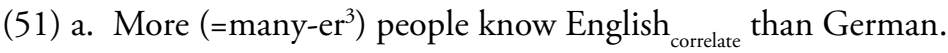

b.

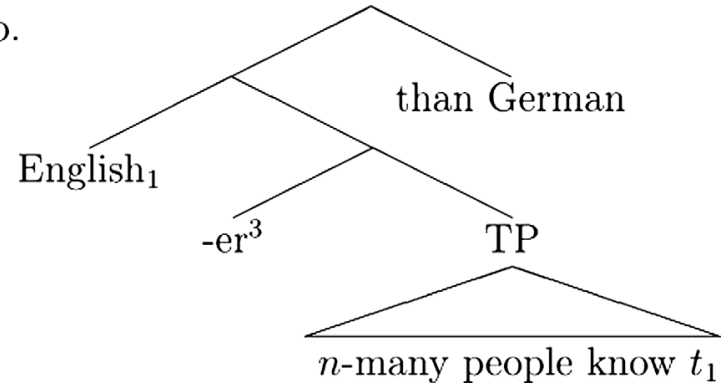

c. 【n-many_people_know_t $t_{1} \rrbracket=\lambda x_{1} \lambda n_{d}\left[n-\right.$ many_people_know_ $\left.x_{1}\right]$

d. $\exists d[[d$-many_people_know_English $] \wedge[d>$ $\max \left(\lambda d^{\prime}\left[d^{\prime}-\right.\right.$ many_people_know_German $\left.\left.\left.]\right)\right]\right]$

In essence, the covert movement of the correlate (as well as the short movement of the comparative morpheme itself and possibly the movement of the standard of comparison) is due to the requirements imposed by the semantics: without this movement, there will be a type failure in composition.

Turning to Greek, the surface syntax of a simple phrasal example like (52) is that in (53a), with the LF phrase structure in (53b) (where linear order is irrelevant).

I Maria pezi kiӨara pjo sixna apo violi. the Maria. NOM plays guitar more often than.PHRASAL violin.ACC 'Maria plays guitar more often than violin.'

(53)

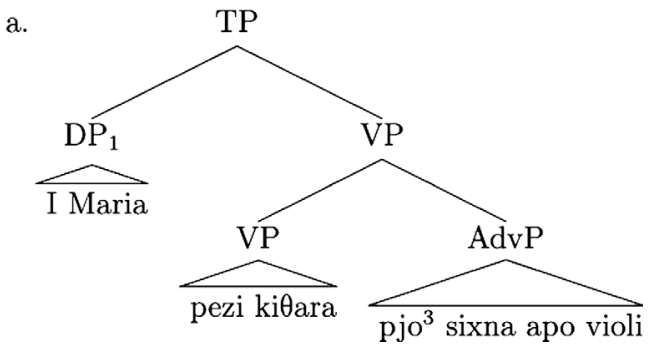


b.

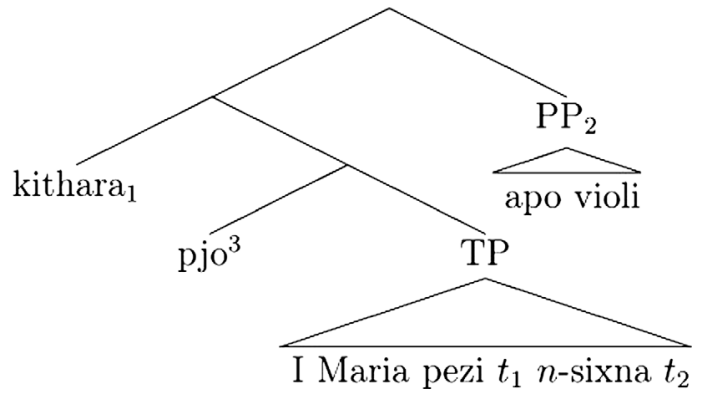

Island effects on this account are not due to restrictions on overt movement, but rather on covert syntactic movement of the correlate. So a crucial example like (31b) above, repeated here in (54a), will have the putative LF in (54b). This LF is not generable, however, by hypothesis, because it relies on an instance of an island-violating movement (I assume that, like English more, Greek perisoter-, decomposes semantically into $p j o^{3}$ and $\left.p o l i\right)$.

(54) a. * Perisoteri anOropi menun sto kratos pu kivernai o Putin more people live in.the state thatgoverns the Putin apo ton Bush.

than.PHRAsAl the Bush.ACC

'More people live in the country that Putin governs than live in the country that Bush governs.'

b.

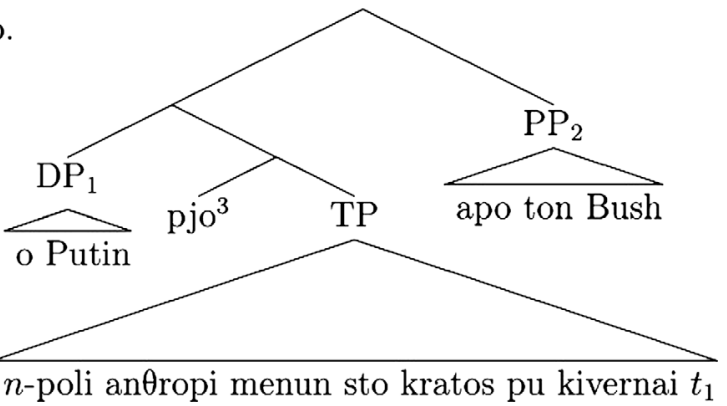

Again, islands must be stated over syntactic representations (here, LFs or the traces of covert movement) or over (covert) syntactic derivations, to rule such examples out. The resulting semantic representation would certainly be wellformed, and interpretable.

There is some additional evidence that is of interest here. It appears that apo comparatives tend to be quite local: that is, separating the comparative morpheme and the standard of comparison by a tensed, finite, non-subjunctive 
clausal boundary leads to decreased acceptability. For some speakers, in fact, the comparative morpheme in apo comparatives must almost be adjacent to the apo phrase (leading for example, to rejection of subject comparatives like Perisoteri an $\theta$ ropi kserun anglika apo germanika 'More people know English than German'). Thus there is some variation in judgment on examples like the following (whose overall acceptability I refrain from marking):

(55) I Maria pjo sixna lei oti ine eksipni apo tin the Maria more often says that is smart than.PHRASAL the Anna.

Anna.

'Maria more often says that she's smart than Anna (says she's smart).'

Speakers for whom such examples are ill-formed might be thought to be using a grammar using a clause-bounded movement operation. If such clauseboundedness is typical of QR (see Farkas and Giannakidou 1996 for discussion), but not of other A-movements, we have a potential argument for preferring the covert movement approach over the overt movement one, for such speakers. Judging the comparative complexity of the two approaches is not my intent here however (as it would require making explicit weightings of the various elements involved in both: the additional movement and case assignment in the overt movement approach vs. the additional movements of the correlate, comparative morpheme, and standard of comparative in the covert movement approach). ${ }^{11}$ In either case, we must countenance movements that are not compatible with purely surfacist approaches to syntax.

If the island sensitivity in Greek phrasal comparatives is due to illicit movement of the correlate for semantic reasons, then such movement must be unnecessary in the reduced clausal comparatives (which show no island effects). And indeed the clausal, two-place comparative morpheme $-e r^{2}$ requires two-degree expressions, not individuals, as its arguments. While there will still be movement (of the remnant), there must not be movement of the correlate. That is, the contrasting focus on the correlate and remnant must suffice to resolve the ellipsis: no LF-movement can be necessary to provide the structures that are used to compute elliptical identity or parallelism (if movement were necessary, we'd expect the reduced clausal and phrasal comparatives to both be sensitive to islands, contrary to fact).

Furthermore, since the overt movement of the remnant in reduced clausal comparatives fails to trigger island effects, it must be the case that the traces of

${ }^{11}$ See Bhatt and Takahashi 2008 for arguments that for phrasal comparatives in Hindi and Japanese, however, the $-e r^{3}$ approach is superior to alternatives. 
that movement are not subject to locality computations at LF, unlike the traces of the LF movement of the correlate in phrasal comparatives. This is essentially the same as adopting the view, first proposed in Aoun et al. (1987), that traces of overt and of covert movement differ in kind, and are subject to separate licensing conditions. The same conclusion is reached by Beck and Kim (1997), Beck (1996), Yoon (2008), and much other work which builds on the observations that some licit overt movements (such as scrambling of certain quantifying elements over certain 'interveners') are illicit when covert (in Beck and Kim's implementation, there are representational constraints barring LF traces - that is, traces that arise via covert movement, which they notate as $t_{L F}$ to distinguish them from traces of overt movement, $t$ ). The covert movement analysis of phrasal comparatives seems to require a similar conclusion: while the traces of the licit overt movement in the reduced clausal comparative do indeed violate islands, they do so only at PF (in a representation which can therefore be repaired by ellipsis); the chain formed by such traces, while interpreted at LF as usual, is not re-subject to LF locality conditions. The traces of the covert movement of the correlate of the phrasal standard of comparison, on the other hand, arise only in the covert part of the derivation and are subject to LF locality constraints on movement.

\subsection{English comparatives}

While it is not my aim to investigate English or any other language here, a brief comparative remark may be in order. English comparatives, as is well known, show a different distribution in the data: the remnant in a reduced clausal or phrasal comparative uniformly shows island sensitivity, as noted by Reinhart (1991) and Lechner $(2001 ; 2004)$. Of course, there is no unambiguous surface way to determine whether these involve phrasal or reduced clausal structures, unlike in Greek.

(56) * More people live in the country that Putin governs than Bush. ( $\neq$ than live in the country that Bush governs)

(57) *Nikos saw more movies when Nana recommended them to him than Elena.

( $\neq$ than Nikos saw when Elena recommended them to him)

(58) *That the dean is going to invite the cleaning lady is more noteworthy than Maria.

( $\neq$ than that the dean is going to invite Maria)

(59) * More people know someone who lives in Russia than in Tibet.

The uniformity of locality effects indicates that a strategy parallel to that underlying the Greek reduced clausal comparatives must be unavailable in English. 
In particular, the kind of movement that extracts the remnant in Greek clausal comparatives-namely the same kind of movement found in sluicing-cannot be the kind employed in English reduced clausal comparatives. This conclusion, in fact, has been reached on independent grounds in earlier work on English. Lechner $(2001 ; 2004)$ shows that English remnants are subject to even stronger locality conditions, parallel to those found in stripping, gapping, and multiple sluicing (allowing extraction out of finite clauses only over bridge and restructuring verbs, typically with bound embedded subjects; similar conditions may apply to Greek phrasal comparatives, in fact, as noted above). ${ }^{12}$ While refining the account of restrictions on remnant movement is not a goal here, such restrictions provide further support for the main claim of this paper, namely that it is impossible to capture the full range of data in this domain without making use of unpronounced syntactic structure. ${ }^{13}$

\section{Conclusion: Eppur, si muove!}

Theories of syntax strive for parsimony in the devices they posit and degree of abstractness they countenance, but this parsimony cannot come at the expense of empirical coverage. The facts from Greek comparatives demonstrate that a certain amount of 'abstract' syntactic representation - abstract in the sense that there are syntactic structures that have no phonological exponence - must be permitted. It continues to be opinio communis that the correct theory of locality of movement, resulting in island effects, is syntactic in the broad sense (that is, computed over syntactic representations or morphosyntactic ones at PF); and in particular, that island effects cannot be fully captured by semantic, pragmatic, or processing mechanisms (see Phillips 2006 for an overview of this

\footnotetext{
${ }_{12}$ While Lechner, in my view correctly, attributes the locality (or 'boundedness', in his term) constraints on English remnants to independent restrictions on the overt movement of the remnant, Reinhart (1991) proposes that the restrictions derive from covert movement of the correlate. These two approaches echo the two options considered in this paper, of course. To capture the difference between English and Greek on Reinhart's analysis, we would have to posit one of two things: either that in English, but not in Greek, covert movement of correlates is required also in reduced clausal comparatives (triggering LF locality considerations in both cases in English, despite the fact that there is no type-driven reason for such movement in reduced clausal comparatives), or that English reduced clausal comparatives have more structure than their Greek counterparts (assimilating them to the island-sensitive fragment answers, instead of to island-insensitive sluices).

${ }^{13}$ And note that while one might imagine a surfacist approach to the Greek facts (in reduced clausal comparatives there are no island effects because there is no movement at all, while in phrasal comparatives the locality effects arise from constraints on scope - applied to the correlate, if this must form a complex quantifier with the standard of comparison, as Reinhart (1991) posits), the uniformity of locality effects in English would remain a puzzle.
} 
debate and discussion). The standard, and persuasive, argument for this position is that dependencies into islands are regularly tolerated as long as a 'movement' dependency is not involved (for example, insensitive to islands are binding of pronominal variables - both those involving bound variable anaphora with quantifiers and those involving resumptive pronouns in languages like Irish and some in situ wh-question construals). Given this, the appearance of island effects in Greek phrasal comparatives is a puzzle if there is no syntactic structure to trigger them. As Culicover and Jackendoff (2005: 246) put it, "If [such] cases ... were ungrammatical, that would be far better evidence of the reality of invisible [sic; intended: inaudible, JM] structure." And indeed it is.

\section{References}

Aelbrecht, Lobke. 2009. You have the right to remain silent: The syntactic licensing of ellipsis. Ph.D. Dissertation, Brussels: Catholic University of Brussels.

Alexiadou, Artemis and Elena Anagnostopoulou. 1999. Raising without infinitives and the nature of agreement. In Sonya Bird, Andrew Carnie, Jason D. Haugen, and Peter Norquest (eds.), Proceedings of the 18th West Coast Conference on Formal Linguistics, 14-26. Somerville, MA: Cascadilla Press.

Ambridge, Ben and Adele E. Goldberg. 2008. The island status of clausal complements: Evidence in favor of an information structure explanation. Cognitive Linguistics 19: 349-381.

Anagnostopoulou, Elena and Martin Everaert. 1999. Towards a more complete typology of anaphoric expressions. Linguistic Inquiry 30: 97-119.

Aoun, Joseph, Norbert Hornstein, David Lightfoot, and Amy Weinberg. 1987. Two notions of locality. Linguistic Inquiry 18(4): 537-577.

Beck, Sigrid. 1996. Quantified structures as barriers for LF movement. Natural Language Semantics 4: 1-56.

Beck, Sigrid. and Shin-Sook Kim. 1997. On wh-and operator scope in Korean. Journal of East Asian Linguistics 6: 339-384.

Bejar, Susana and Diane Massam. 1999. Multiple case checking. Syntax 2(2): 65-79.

Bhatt, Rajesh and Roumyana Pancheva. 2004. Late Merge of Degree Clauses. Linguistic Inquiry 35: $1-45$.

Bhatt, Rajesh and Shoichi Takahashi. 2008. Reduced and unreduced phrasal comparatives, (unpublished ms.) University of Massachusetts, Amherst and University of Tokyo. [http:// people.umass.edu/bhatt/papers/glow-phrasal.pdf]

Bittner, Maria and Ken Hale. 1996. The structural determination of case and agreement. Linguistic Inquiry 27: 1-68.

Bošković, Željko. 2004. Be careful where you float your quantifiers. Natural Language and Linguistic Theory 22: 681-742.

Chomsky, Noam. 1972. Some empirical issues in the theory of transformational grammar. In Stanley Peters (ed.), The goals of linguistic theory, 63-130. Englewood Cliffs, NJ: PrenticeHall.

Chung, Sandra, William Ladusaw, and James McCloskey. 1995. Sluicing and logical form. Natural Language Semantics 3: 239-282.

van Craenenbroeck, Jeroen and Anikó Lipták. 2006. The crosslinguistic syntax of sluicing: Evidence from Hungarian relatives. Syntax 9: 248- 274. 
Culicover, Peter and Ray Jackendoff. 2005. Simpler Syntax. Oxford: Oxford University Press.

Erteschik-Shir, Nomi. 1973. On the nature of island constraints. Ph.D. thesis, MIT.

Erteschik-Shir, Nomi. 2007. Information Structure: The Syntax-Discourse Interface. Oxford: Oxford University Press.

Evans, Nicholas. 1995. A grammar of Kayardild. Berlin: Mouton de Gruyter.

Farkas, Donka and Anastasia Giannakidou. 1996. How clause-bounded is the scope of universals. In Tracy Gallway (ed.), Proceedings of Semantics and Linguistic Theory (SALT 6), 35-52. Ithaca, NY: CLC Publications, Cornell University.

Fox, Danny and Howard Lasnik. 2003. Successive-cyclic movement and island repair: The difference between sluicing and VP-ellipsis. Linguistic Inquiry 34: 143-154.

Giannakidou, Anastasia. 1998. Polarity sensitivity as (non)veridicality. Amsterdam: John Benjamins.

Giannakidou, Anastasia. in press. Time for mood: The subjunctive revisited. Lingua.

Giannakidou, Anastasia and Melita Stavrou. 2009. On metalinguistic comparatives and negation in Greek. In C. Halpert, J. Hartman, and D. Hill (eds.), MIT Working Papers in Linguistics 57: Proceedings of the 2007 Workshop on Greek syntax and semantics. Cambridge: MIT.

Giannakidou, Anastasia and Suwon Yoon. 2008. Metalinguistic comparatives in Greek and Korean: Attitude semantics, expressive content, and negative polarity items, (unpublished ms.) University of Chicago. [http://home.uchicago.edu/ giannaki/pubs/FINAL. GiannYoon.2008]

Giannakidou, Anastasia and Suwon Yoon. 2008. The landscape of metalinguistic comparatives. Proceedings of the 10th Seoul International Conference on Generative Grammar. Seoul: Hankook Publishing.

Ginzburg, Jonathan and Ivan Sag. 2000. Interrogative investigations. Stanford: CSLI.

Hankamer, Jorge. 1973. Why there are two than's in English. In Claudia Corum, T. Cedric Smith-Stark, and Ann Weiser (eds.), Proceedings of the 8th annual meeting of the Chicago Linguistic Society. Chicago, IL: Chicago Linguistic Society.

Harris, Zellig S. 1957. Co-occurrence and transformation in linguistic structure. Language 33: 293-340.

Heim, Irene. 1985. Notes on comparatives and related matters, (unpublished ms.) University of Texas at Austin.

Jäger, Gerhard. 2006. Indefinites and sluicing: A type-logical approach. Ms., University of Bielefeld. (To appear in revised form in Language and Computation.)

Joseph, Brian D. 1979. Raising to Oblique in Modern Greek. In Proceedings of the Fifth Meeting of the Berkeley Linguistics Society, 114-128.

Joseph, Brian D. 1990. Is Raising to prepositional object a natural language grammatical construction? In Brian D. Joseph and Paul M. Postal (eds.), Studies in Relational Grammar 3, 261-276. Chicago, IL: University of Chicago Press.

Kayne, Richard S. 2004. Prepositions as probes. In Adriana Belletti (ed.), Structures and beyond: The cartography of syntactic structures, vol. 3, 192-212. Oxford: Oxford University Press.

Kennedy, Christopher. 1999. Projecting the adjective. New York: Garland Press.

Kennedy, Christopher. 2002. Comparative deletion and optimality in syntax. Natural Language and Linguistic Theory 20: 553-621.

Kennedy, Christopher. 2003. Ellipsis and syntactic representation. In Susanne Winkler and Kerstin Schwabe (eds.), The interfaces: Deriving and interpreting omitted structures, 29-53. Amsterdam: John Benjamins.

Kennedy, Christopher and Jason Merchant. 2000. Attributive comparative deletion. Natural Language and Linguistic Theory 18: 89-146.

Kluender, Robert. 2004. Are subject islands subject to a processing account? In Benjamin Schmeiser, Vineeta Chand, Ann Kelleher and Angelo Rodriguez (eds.), WCCFL 23 Proceedings, 101-125. Somerville, MA: Cascadilla Press.

Koopman, Hilda. 2000. The syntax of specifiers and heads. New York: Routledge. 
Kuno, Susumu and Jane R. Robinson. 1972. Multiple wh questions. Linguistic Inquiry 3: 463-487. Lasnik, Howard and Myung-Kwan Park. 2003. The EPP and the subject condition under sluicing. Linguistic Inquiry 34: 649-660.

Lechner, Winfried. 2001. Reduced and phrasal comparatives. Natural Language and Linguistic Theory 19(4): 683-735.

Lechner, Winfried. 2004. Ellipsis in comparatives. Berlin: Mouton de Gruyter.

Merchant, Jason. 2000. Islands and LF-movement in Greek sluicing. Journal of Greek Linguistics 1: 41-64.

Merchant, Jason. 2001. The syntax of silence: Sluicing, islands, and the theory of ellipsis. Oxford: Oxford University Press.

Merchant, Jason. 2004. Fragments and ellipsis. Linguistics and Philosophy 27: 661-738.

Merchant, Jason. 2006. 'Small structures': A sententialist perspective. In Ljiljana Progovac, Kate Paesani, Elena Casielles, and Ellen Barton (eds.), The syntax ofnonsententials: Multidisciplinary perspectives, 73-91. Amsterdam: John Benjamins.

Merchant, Jason. 2008. Variable island repair under ellipsis. In Kyle Johnson (ed.), Topics in ellipsis, 132-153. Cambridge: Cambridge University Press.

Merchant, Jason. 2009. Polyvalent case, geometric hierarchies, and split ergativity. In Jackie Bunting, Sapna Desai, Robert Peachey, Chris Straughn, and Zuzana Tomkova (eds.), Proceedings of the 42nd annual meeting of the Chicago Linguistic Society. Chicago, IL: Chicago Linguistic Society.

McCloskey, James. 1984. Raising, subcategorization and selection in Modern Irish. Natural Language and Linguistic Theory 1: 441-487.

Park, Myung-Kwan. 2004. Phases, cyclicity, and extraction out of ellipsis in English, (unpublished ms.) Dongguk University.

Philippaki-Warburton, Irene. 1993. The subjunctive mood and the syntactic status of the particle $n a$ in Modern Greek. Folia Linguistica XXVIII 3-4: 297-326.

Phillips, Colin. 2006. The real-time status of island phenomena. Language 82 (4): 795-823.

Reinhart, Tanya. 1991. Elliptic conjunctions - Non-quantificational QR. In Asa Kasher (ed.), The Chomskyan turn, 360-384. Cambridge, MA: Blackwell.

Ross, John R. 1969. Guess who? In Robert Binnick, Alice Davison, Georgia Green, and Jerry Morgan (eds.), Papers from the 5th regional meeting of the Chicago Linguistic Society, 252286. Chicago, IL: Chicago Linguistic Society.

Roussou, Anna. 2000. On the left periphery: modal particles and complementizers. Journal of Greek Linguistics 1: 63-93.

Schlangen, David. 2003. A coherence-based approach to the interpretation of non-sentential utterances in dialogue. Ph.D. Dissertation, School of Informatics, University of Edinburgh.

Stainton, Robert. 2006. Words and thoughts. Oxford: Oxford University Press.

Terzi, Arhonto. 2005. Locative prepositions as possessums. In Marina Mattheoudakis and Angeliki Psaltou-Joycey (eds.), Selected papers on theoretical and applied linguistics, 130-144. Thessaloniki: Aristotle University Thessaloniki.

Theophanopoulou-Kontou, Dimitra. 1992. Isynthetes prothetikes phrasistis N.E. ke i dhomi tus [Complex prepositional phrases in Modern Greek and their structure]. In Proceedings of the 13th annual meeting of the department of linguistics, 311-330. Thessaloniki: Aristotle University Thessaloniki.

Xeila-Markopoulou, Despina. 1986. Ta sigritika tis Neas Elinikis [Comparatives in Modern Greek]. Ph.D. Dissertation, University of Athens.

Yoon, James. 2004. Non-nominative (major) subjects and case stacking in Korean. In P. Bhaskararao and K. V. Subbarao (eds.), Non-nominative subjects, vol. 2: 265-314. Amsterdam: John Benjamins.

Yoon, Suwon. 2008. An argument/adjunct asymmetry in intervention effects: A novel argument for LF constraints, (unpublished ms.) University of Chicago. 